\title{
Orbitopterional Approach for the Resection of a Suprasellar Craniopharyngioma: Adapting the Strategy to the Microsurgical and Pathologic Anatomy
}

\author{
Vincent Nguyen ${ }^{1,2}$ Jaafar Basma ${ }^{1,2}$ Paul Klimo ${ }^{2}$ Jeffrey Sorenson ${ }^{1,2} \quad$ L. Madison Michael II ${ }^{1,2}$ \\ ${ }^{1}$ Department of Neurosurgery, University of Tennessee, Memphis, \\ Tennessee, United States \\ 2 Semmes-Murphey Neurologic and Spine Institute, Memphis, \\ Tennessee, United States \\ Address for correspondence L. Madison Michael, MD, Department of \\ Neurosurgery, University of Tennessee, 847 Monroe Avenue, \\ Suite 427, Memphis, TN 38163, United States \\ (e-mail: mmichael@semmes-murphey.com).
}

J Neurol Surg B 2018;79(suppl S3):S239-S240.

Abstract



Keywords
- cisterns
- internal carotid artery
- optic nerve
- opticocarotid
- suprasellar
- craniopharyngioma
- orbitopterional

Conflict of Interest

None.

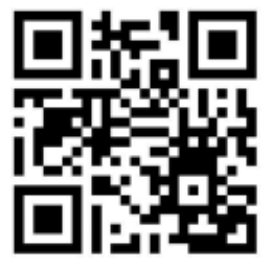

received

October 15, 2017

accepted after revision

December 7, 2017

published online

January 25, 2018
Objectives To describe the orbitopterional approach for the resection of a suprasellar craniopharyngioma with emphasis on the microsurgical and pathological anatomy of such lesions.

Design After completing the orbitopterional craniotomy in one piece including a supraorbital ridge osteotomy, the Sylvian fissure was split in a distal to proximal direction. The ipsilateral optic nerve and internal carotid artery were identified. Establishing a corridor to the tumor through both the opticocarotid and optic cisterns allowed for a wide angle of attack. Using both corridors, a microsurgical gross total resection was achieved. A radical resection required transection of the stalk at the level of the hypothalamus. Photographs of the region are borrowed from Dr Rhoton's laboratory to illustrate the microsurgical anatomy. Understanding the cisternal and topographic relationships of the optic nerve, optic chiasm, and internal carotid artery is critical to achieving gross total resection while preserving normal anatomy.

Participants The surgery was performed by the senior author assisted by Dr. Jaafar Basma. The video was edited by Dr. Vincent Nguyen.

Outcome Measures Outcome was assessed with extent of resection and postoperative visual function.

Results A gross total resection of the tumor was achieved. The patient had resolution of her bitemporal hemianopsia. She had diabetes insipidus with normal anterior pituitary function.

Conclusions Understanding the microsurgical anatomy of the suprasellar region and the pathological anatomy of craniopharyngiomas is necessary to achieve a good resection of these tumors. The orbitopterional approach provides the appropriate access for such endeavor. The link to the video can be found at: https://youtu.be/Be6dtYIGqfs. www.thieme.com/skullbasevideos

www.thieme.com/jnlsbvideos
DOI https://doi.org/

10.1055/s-0038-1623525. ISSN 2193-6331. (c) 2018 Georg Thieme Verlag KG
Stuttgart · New York
License terms

(c) (i) $\ominus$ (\$) 


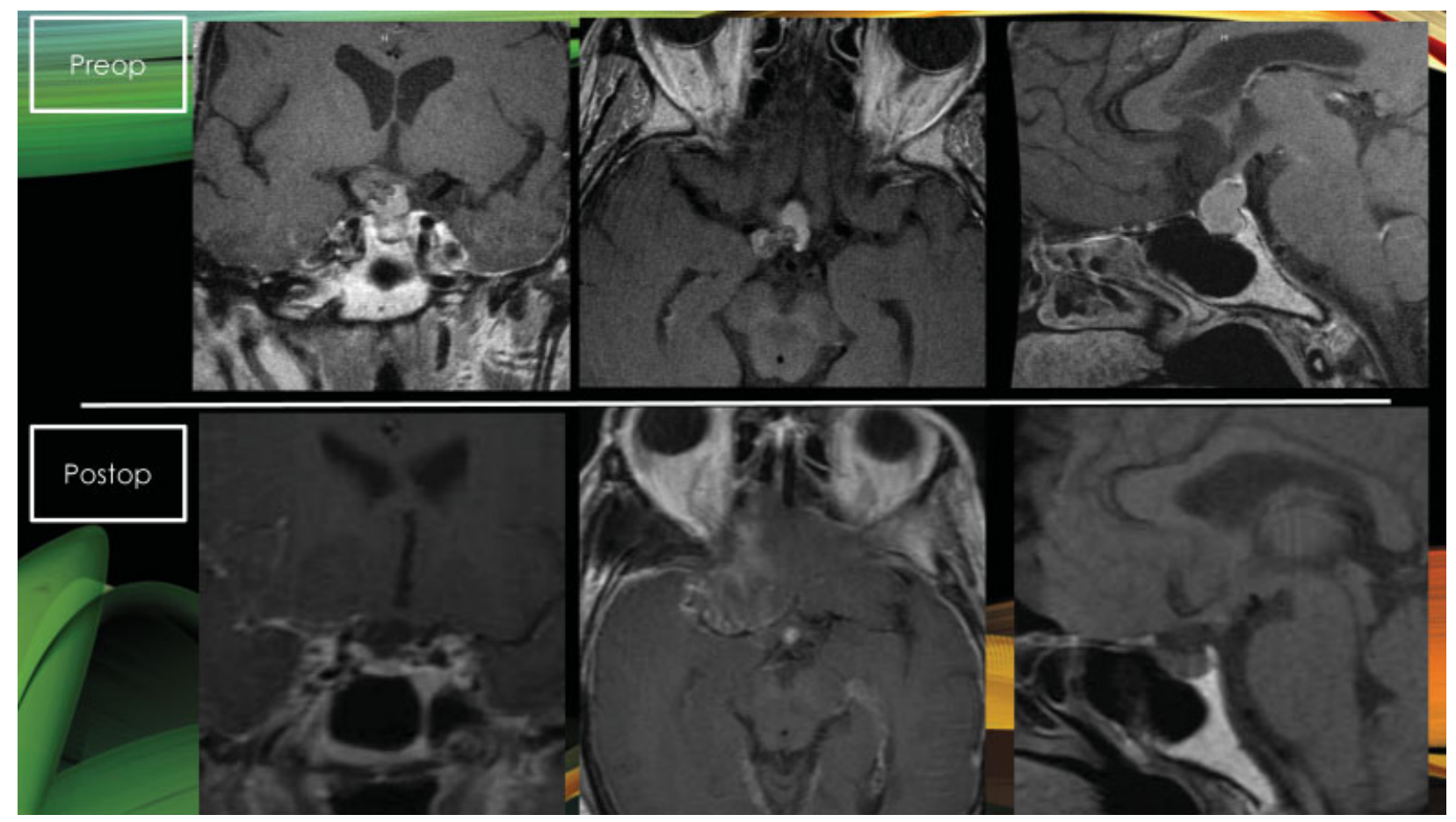

Fig. 1 Gross total resection of this suprasellar craniopharyngioma was achieved as demonstrated by these pre- and postoperative imaging studies.

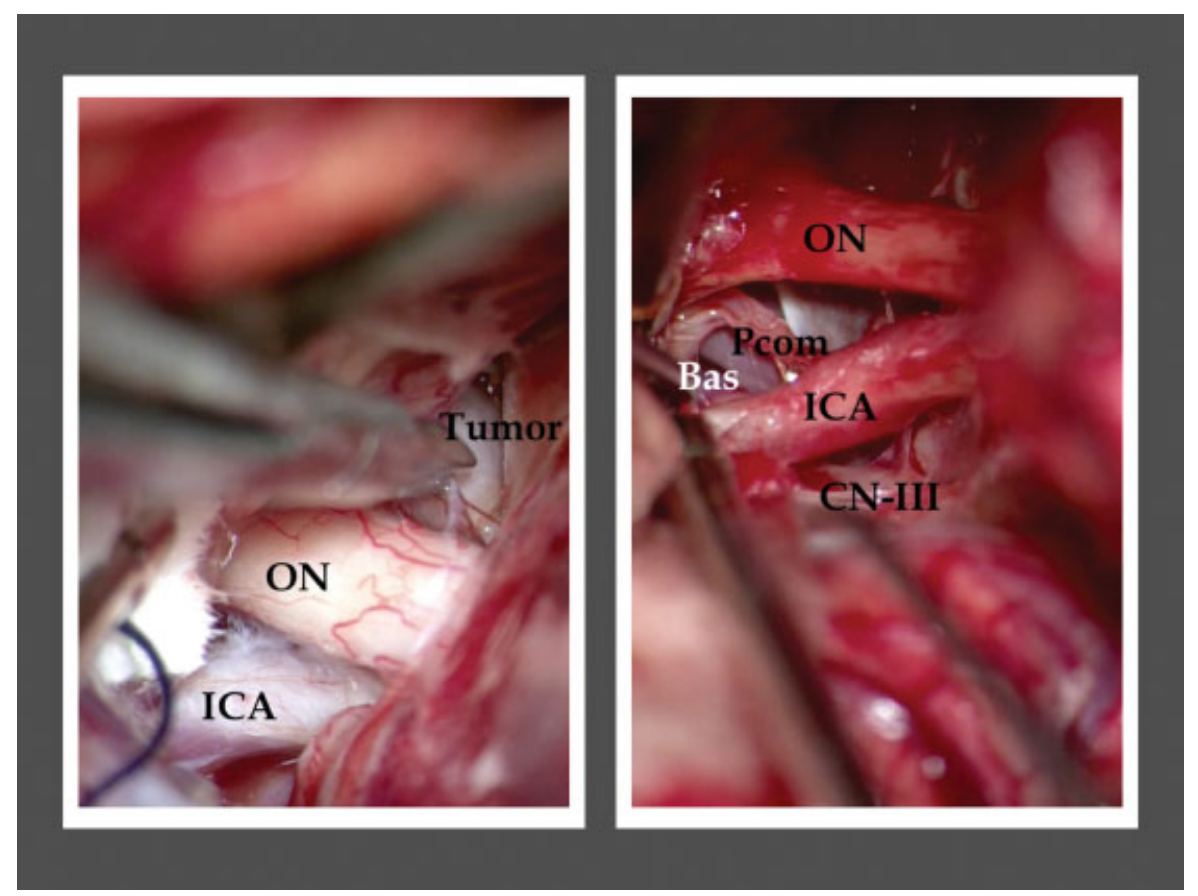

Fig. 2 This suprasellar craniopharyngioma was gross totally resected through an orbitopterional approach, utilizing the optic and opticocarotid cisterns as corridors for attack. CN-III; cranial nerve III; ICA, internal carotid artery; ON, optic nerve. 